\title{
As artes e o desenvolvimento cultural do ser humano*
}

Ricardo Ottoni Vaz Japiassu**

\begin{abstract}
RESUMO: O artigo situa historicamente a produção e a publicação do estudo vigotskiano sobre a psicologia das artes. Identifica nele as origens do pensamento psicológico de L.S. Vygotsky sobre o qual se estrutura a elaboração da teoria histórico-cultural do funcionamento mental superior. Expõe a teoria da reação estética e o conceito de catarsis vigotskianos.
\end{abstract}

Palavras-chave: Estética, teatro, literatura, vanguarda russo-soviética, psicologia cultural

\section{Apresentação}

Este artigo tem como objetivo socializar alguns aspectos da criação e da recepção artísticas abordados por Vygotsky em seu estudo Psicologia das artes, ${ }^{1}$ que foi escrito e apresentado ao Instituto de Psicolo-

* Este artigo foi elaborado a partir de monografia intitulada "A psicologia das artes de Lev Semenovich Vygotsky e a estética cênica do teatro de vanguarda russo-soviético: Possíveis entroncamentos", apresentada como condição parcial de aprovação na disciplina "A intertextualidade entre a poética do circo e a poética do teatro de vanguarda russosoviético", ministrada pela professora-doutora Reni Chaves Cardoso Sampaio Zacchi no curso de pós-graduação stricto-sensu da Escola de Comunicação e Artes-ECA da Universidade de São Paulo-USP, durante o segundo semestre de 1997.

** Professor da Universidade do Estado da Bahia-UNEB, Mestrando em Artes Cênicas da ECA/ USP, Licenciado e Bacharel em Teatro pela Universidade Federal da Bahia-UFBa, Membro da Educational Theater Association-TEA. Email: rjapias@ibm.net 
gia de Moscou, em 1925, como tese de doutoramento (Vygotsky 1997, p. XV). Não se tem conhecimento até aqui de nenhuma publicação em língua portuguesa desse importante trabalho de L.S. Vygotsky, justificando-se assim esforços no sentido de divulgá-lo. ${ }^{2} \mathrm{O}$ artigo apresenta os resultados parciais obtidos com o desenvolvimento da pesquisa bibliográfica necessária à investigação denominada "Jogos teatrais na escola pública: Aspectos do desenvolvimento cultural de crianças e adolescentes com a representação simbólico-dramática e a linguagem teatral no ensino regular de Teatro na educação infantil e séries iniciais do ensino fundamental em São Paulo-SP/Brasil", sob a orientação da professora-doutora Maria Lúcia de S.B. Pupo, da Escola de Comunicação e Artes-ECA da Universidade de São Paulo-USP.

A partir de uma contextualização histórica da época em que viveu e atuou L.S. Vygotsky demonstrar-se-á sua estreita ligação com integrantes da vanguarda artística russo-soviética, especialmente no campo do teatro e do cinema. A seguir, com base em seu estudo Psicologia das artes serão expostos o conceito vygotskiano de catarsis e sua Teoria da Reação Estética, discutindo-os e identificando-os como ponto de partida para o desenvolvimento do seu pensamento psicológico - sobre o qual se assentam a Teoria Histórico-Cultural do Desenvolvimento das Funções Psicológicas Superiores e a Psicologia Sócio-Histórica.

\section{Vygotsky e o teatro de vanguarda russo-soviético}

Lev Semenovich Vygotsky nasceu em Orsha (Bielo-Rússia) aos 5 de novembro de $1896^{3}$ e foi o segundo de oito filhos de um casal da comunidade judaica de Gomel, cidade situada a 400 milhas ao sudoeste de Moscou. Seu pai trabalhou no Banco Unido de Gomel e chegou a chefiar uma seção do Banco Comercial de Moscou após a revolução bolchevista. Embora sua mãe fosse professora licenciada (Blanck 1996, p. 32), tanto sua educação como a de seus irmãos foram confiadas a um tutor particular (Van Der Veer e Valsiner 1996, p. 17). Quando adolescente, seus interesses se concentraram na literatura e nas artes, iniciando nessa época estudos sobre o Hamlet de Shakespeare - que viria a ser o tema de seu trabalho de conclusão do curso de Direito e Literatura na Universidade de Moscou. Esse trabalho foi posteriormente reestruturado e incorporado à Psicologia das artes. Em 1917, concluída sua formação universitária em 
Moscou, retornou à cidade de Gomel logo após a revolução e passou a lecionar em escolas estaduais. Ali ocupou muitas posições de destaque na vida cultural da cidade e coordenou um círculo de estudos intitulado Segundas-feiras literárias no qual se discutia a produção teatral de Shakespeare, Goethe, Tchekov, Maiakovski, Pushkin e de outros dramaturgos. Guillermo Blanck, professor-pesquisador da Universidade de Buenos Aires, ajuda a compreender melhor a produção intelectual vigotskiana nesse período ao esclarecer que:

As atividades de Vygotsky durante seus anos em Gomel eram parte de um dos mais importantes movimentos intelectuais de nosso século. Pinturas futuristas e suprematistas, assim como esculturas construtivistas, eram expostas nas ruas, trens, caminhões e navios. Os intelectuais inovadores não apenas se devotavam pessoalmente a um trabalho criativo específico, mas participavam do trabalho de instituições. Kandinsky, por exemplo, era vice-presidente da Academia de Artes e Ciências de Moscou. Malevich presidia a de Petrogrado, onde o arquiteto Tatlin, autor do famoso monumento à Terceira Internacional, chefiava um Departamento. Chagall era Ministro das Belas-Artes em Vitebsk. O versátil Rodchenko organizava programas de educação artística.(...) Meyerhold dirigia a seção teatral do Comissariado Popular para a Educação e Stanislavsky presidia o Teatro Artístico de Moscou. Gabo e seu irmão Pevsner representavam o grupo construtivista e Maiakovski, a Frente Esquerdista de Artes (Lef). Eisenstein, que devido ao seu conhecimento de engenharia organizou a construção de defesas durante a Guerra Civil, foi se tornar o professor dirigente do Instituto Estatal de Cinematografia. O pedagogo Makarenko (1985) fundou a Colônia Gorky para a reeducação de delinqüentes juvenis de rua.

Devemos acrescentar a esses nomes, representando diversos campos, os de Lissitsky, Vertov, Gorky, Bugacov e Sholokhov (...) A escola formalista de Petrogrado estava revolucionando a teoria literária com suas investigações. Bakhtin e seu círculo, a partir de outro ponto de vista, estavam produzindo no mesmo campo de estudos. Lenin comandava o Estado e Lunacharsky era o Ministro da Cultura e da Educação. (1996, pp. 35-36)

Em Gomel, Vygotsky chefiou a Seção de Teatro do Departamento de Educação Popular onde participou ativamente na seleção do repertório, na 
concepção de cenários, na direção de muitas encenações e foi o responsável pela coluna de teatro no jornal local Polesskaja Pravda. Segundo René Van Der Veer e Jaan Valsiner (1996, p. 23): "Ele nunca perdeu seu interesse pelo Teatro, encontrava-se regularmente com cenógrafos e diretores (como Eisenstein) e, perto do fim de sua vida, publicou um trabalho sobre a psicologia do ator." ${ }^{\prime 4}$ Victoriano Imbert, tradutor espanhol de Psicologia das artes, acredita que uma prova da amizade de Vygotsky com Eisenstein e da atenção especial que este último dirigia às idéias do eminente psicólogo russo-soviético é o fato de no exemplar de Psicologia das artes, encontrado nos arquivos pessoais do cineasta e diretor teatral, estarem sublinhadas todas as passagens em que Vygotsky assinala a contradição inerente à elaboração da obra de arte (1972, p. 184). Além disso, para Imbert, a interpretação vigotskiana das artes como forma de conhecimento, próximo ao científico, teria se manifestado com particular nitidez nas idéias estéticas de Berthold Brecht (em sua concepção de um Teatro Épico) e de Eisenstein (na formulação do seu Cinema Intelectual) (1972, pp. 71-72). De fato, a concepção vigotskiana das artes como sistemas de representação semióticos as desincumbia do compromisso com a "imitação" ou "cópia fotográfica" da realidade, instituindo-as como realidades com "leis" próprias (1972, p. 95).

O teatro de vanguarda russo-soviético, contemporâneo das idéias de Vygotsky, fundamentava-se numa estética didático-marxista, fortemente informada pelos pressupostos da escola formalista e futurista. No entanto, V.V. Maiakóvski, poeta, dramaturgo e ator, um dos líderes da renovação estética das artes na Rússia pós-revolucionária, fazia questão de esclarecer que todo o trabalho de pesquisa formal na poesia, nas artes plásticas, no teatro e no cinema daquela época não era "um fim em si estético, mas um laboratório para a melhor compreensão dos fatos da atualidade (...) Uma obra não se torna revolucionária unicamente pela sua novidade formal. Uma série de fatos, o estudo de seu fundamento social, Ihe imprime força. Mas, a par do estudo sociológico, existe o estudo do aspecto formal" (apud Schnaiderman 1984, pp. 222-238). Os estudos e as pesquisas cênicas que objetivavam a renovação do teatro russo nas primeiras décadas do século XX buscavam alternativas para os valores estéticos burgueses dominantes até então nos palcos da Rússia. As mudanças pensadas para a cena traduziam o anseio e a utopia da construção de novas relações de trabalho, produção e distribuição do poder na sociedade socialista soviética. Assim como a psicologia, as artes necessitavam adequar-se à concepção materialista histórica da realidade e do mundo. Um importante passo nesse sentido foi dado com 
os movimentos formalista e futurista. Segundo Ripellino (1971, p. 12), "após a epopéia de Outubro, o futurismo foi favorecido pelo regime e quase se Ihe atribuiu uma tendência oficial". Tanto o Formalismo como o Futurismo influenciaram as pesquisas cênicas das mulheres e dos homens de teatro russos empenhados na descoberta de novos caminhos para as encenações teatrais. A análise crítica dos postulados estéticos do Formalismo feita por Vygotsky em Psicologia das artes não o impediu de reconhecer nesse movimento um avanço em direção à concepção marxista das artes, especialmente através da formulação do princípio de estranhamento (resgatado e desenvolvido posteriormente por B. Brecht, na Alemanha dos anos 40, ao propor o Teatro Épico). Examinando-se relatos das pesquisas cênicas e preocupações estéticas de V.E. Meyerhold, ator e encenador russo contemporâneo de Vygotsky e Eisenstein, conclui-se que o aprofundamento de seus estudos objetivava a operacionalização cênica desse efeito de estranhamento, aliás, como ele mesmo chegou a admitir: "No teatro da convenção o espectador não esquece em nenhum momento que diante dele está um ator que representa, e o ator não esquece que diante dele está a platéia; sob seus pés, o palco e ao redor, a cenografia. É a mesma coisa com um quadro: ao olhá-lo não se pode esquecer por um segundo que se trata de tintas, tela, pincel (...)" (apud Cavaliere 1996, p. 107).

Desde os primeiros experimentos com as convenções, máscaras e personagens da commedia dell'arte, passando pela apropriação da tradição popular grotesca do teatro de feira russo, dos princípios técnicos da pantomima, do simbolismo cênico até a formulação da biomecânica, o objetivo estético de Meyerhold é a afirmação da teatralidade, de um teatro de convenção e estilização, do teatro como sistema de representação semiótico (Cavaliere 1996, p. 100). A concepção do teatro como sistema de representação simbólico, quer dizer, como linguagem que possui regras próprias, essencialmente convencional, é o ponto de partida para as críticas de Vygotsky dirigidas ao Teatro Artístico de Moscou por ocasião da encenação do Hamlet de Shakespeare, sob a supervisão de Stanislavski. Esse mesmo entendimento do fenômeno teatral é comungado por V.E. Meyerhold, quando afirmava ser "através da convenção que as estátuas de mármore e de bronze não são pintadas. (...) Onde se encontra a arte, encontra-se também a convenção" (apud Cavaliere 1996, p. 105). É precisamente esse conceito semiótico e portanto histórico-cultural do teatro que levou Meyerhold, originalmente ator e diretor do Teatro Artístico de Moscou, a discordar de certos princípios stanislavskianos, levando-o a deixar a companhia de Stanislavski na primavera de 1902. No entanto, as 
divergências entre suas diferentes concepções cênicas não os impediram de voltar a trabalhar juntos em 1905 no teatro-estúdio da rua Povarskáia e em 1938 no teatro de ópera Stanislavski (Ripellino 1996, p. 101). A ênfase na teatralidade é um recurso antiilusionista e deliberadamente contrário à perspectiva psicologizante das encenações "naturalistas" que caracterizavam as produções do Teatro Artístico de Moscou. Stanislavski, ao aprofundar a abordagem psicológica das personagens, alinhava-se a uma perspectiva introspeccionista da psicologia muito criticada pelas tendências associacionista (defendida por Pavlov) e histórico-cultural (advogada por Vygotsky). A psicologia marxista deveria entender os homens e as muIheres como seres nos quais, sobre a base biológica, operam as injunções socioculturais, historicamente determinadas. Assim sendo, era necessária a construção de personagens que evidenciassem a dimensão simbólica, cultural, de domínio e transformação da natureza pela mão, ferramentas e instrumentos produzidos pelo ser humano.

O sistema biomecânico de preparação de atores formulado por Meyerhold lograva introduzir, na formação do profissional da cena, muito dos conhecimentos adquiridos com a doutrina dos reflexos condicionados, defendida por Pavlov e Békhterev, que ambiciona explicar o mecanismo da origem e da produção das reações adquiridas com base na cadeia reativa estímulo-resposta. O mecanismo do reflexo condicionado e sua doutrina eram vistos na Rússia pós-revolucionária como o elo de ligação entre as leis biológicas dos dispositivos hereditários estabelecidos por Darwin e as leis sociológicas estabelecidas por Karl Marx, no entanto Vygotsky, embora reconhecendo o valor da Reflexologia, ${ }^{5}$ defendia a necessidade de construção de uma perspectiva mais abrangente da psicologia, que reconhecesse as especificidades do funcionamento mental humano quando comparado ao funcionamento mental animal. Ele considerava que a Reatologia limitava o estudo do comportamento humano a seu aspecto biológico, ignorando a experiência histórica e social adquirida durante a evolução filogenética e a importância do papel fundamental da psique e da consciência sobre as ações e reações do ser humano. Sabe-se que Meyerhold, a partir da segunda década deste século, deixa de se valer unicamente dos recursos cênicos acrobáticobiomecânicos embora continue a desenvolver pesquisas para a proposição de um teatro não-ilusionista (Cavaliere 1996, p. 100). O próprio Meyerhold revela sua preocupação em desenvolver uma linguagem teatral assentada sobre os fundamentos materialistas históricos, que enfatizasse a consciência do ator: "A arte deve se fundar sobre bases científicas e toda a criação do artista deve ser consciente. A arte do ator 
é fundada sobre a organização de seu material, isto é, o ator deve saber utilizar corretamente os meios expressivos de seu corpo" (apud Cavaliere 1996, p.116) (Grifo meu).

Embora não seja possível afirmar categoricamente que o pensamento psicológico vigotskiano tivesse exercido uma influência decisiva sobre a concepção cênica meyerholdiana, há indícios de que Meyerhold tenha entrado em contato com suas idéias - especialmente quando se considera a amizade em comum de ambos com S. Eisenstein. V.V. Davydov e V.P. Zinchenko, psicólogos russos, asseguram que:

(...) a idéia de base simbólica e de signo da consciência, que Vygotsky desenvolveu, relacionava-se com a teoria e a prática do simbolismo russo, cuja manifestação mais nítida estava na poesia, no teatro e no cinema. O simbolismo, na arte, opõe-se ao naturalismo, como fica claramente evidenciado nos trabalhos e na poesia de V. Ivanov e A. Belyi; nos livros, peças e filmes de $V$. Meierkhold e $S$. Eisenstein. Para Vygotsky, um extraordinário conhecedor de arte, essa oposição assumia a forma de um protesto científico contra o naturalismo na psicologia (...) Vygotsky conhecia pessoalmente vários desses representantes da ciência, da cultura e da arte mencionados anteriormente (alguns eram seus amigos), e conheceu os outros através de suas publicações. Se descrevemos seu histórico cultural, certamente não é para sugerir que ele, simplesmente, tomou emprestadas várias idéias de predecessores e contemporâneos seus, embora isso também tenha acontecido. Em ciência, não pode ser de outra maneira. Mas importante para nós é que o leitor sinta o espírito da época, a atmosfera de investigação daquela época; é importante mostrar que o problema da atividade e da consciência humanas interessava a muitos representantes renomados da ciência e da cultura (...) A tarefa de reflexão e compreensão dessas relações e de realizações de uma possível síntese das idéias desenvolvidas acerca da atividade e da consciência humanas por esses notáveis representantes da arte, da filosofia, da lingüística, da biologia evolucionista e da psicologia é a tarefa mais interessante para os historiadores da ciência. (1995, p. 154) (Grifos meus).

De fato, na Rússia pós-revolucionária os artistas e a intelectualidade estavam empenhados em discutir as bases ideológicas e estéticas sobre as quais deveriam se assentar as ciências e as artes da nova sociedade 
socialista soviética. A questão da consciência estava posta como eixo central do desenvolvimento total, multilateral, do ser humano, e as artes, em particular o cinema e o teatro (poderosos veículos de comunicação não escrita para a maioria analfabeta da Rússia da época), deveriam assumirse como fórum, arena, espaço de luta onde seriam travadas batalhas de idéias, pensamentos e concepções da organização sociopolítica e econômico-cultural do país. O teatro fundado dramática e cenicamente pela vanguarda russo-soviética é um teatro de propaganda das novas relações de produção, trabalho e poder estabelecidas com a organização social e política derivada da revolução de 1917: é um veículo para a propaganda explícita dos valores estéticos e dos pressupostos materialistas históricos, marxistas, como afirmava Maiakóvski (Schnaiderman 1978, pp. 127-133).

O professor-doutor Michael Cole, que foi orientado por A.R. Luria ${ }^{6}$ em Moscou, entre o final de 1960 e o início dos anos 70, e atualmente dirige o Laboratório de Cognição Humana Comparada ${ }^{7}$ do Departamento de Comunicação da Universidade da Califórnia de San Diego-UCSD, confirma os vínculos de Vygotsky e de seus colaboradores com artistas da vanguarda russo-soviética, engajados na construção de uma nova estética para as artes:

Ele [Luria] e Vygotsky, por exemplo, encontravam-se regularmente com Sergei Eisenstein, para discutir como as idéias abstratas que estavam no coração do materialismo histórico poderiam ser incorporadas em imagens visuais projetadas sobre uma tela de cinema. Por acaso, Alexander Zaporozhets [colaborador do grupo de pesquisas liderado por Vygotsky], que havia sido ator na Ucrânia antes de ir a Moscou, e havia sido recomendado a Sergei Eisenstein, tornouse psicólogo. Ao final da década de 20 ele tinha o papel de "olheiro" da psicologia no mundo do cinema, freqüentando as discussões de Eisenstein que ele então relatava a Vygotsky e Luria. Eisenstein utilizou a ajuda de seus amigos psicólogos não só para resolver o difícil problema da tradução de conceitos verbais e visuais, mas também para resolver o problema empírico da avaliação do sucesso. Com sua ajuda, ele elaborou questionários que apresentava à sua audiência, composta de trabalhadores, estudantes e camponeses, para determinar se eles entendiam suas imagens como ele havia pretendido. É uma medida da extensão de seus interesses que, para Alexander Romanovich (Luria), a relação entre modos de representação de idéias e modos de pensamento não tenha sido menos importante no cinema que no laboratório. (1992, p. 211) (Grifo meu). 
Os biógrafos de L.S. Vygotsky consideram o período de Gomel como marco da origem do seu pensamento psicológico e afirmam que a principal parte de sua tese Psicologia das artes foi ali escrita. Muitos deles concordam que o desejo de Vygotsky em aprofundar suas teorizações sobre os procedimentos conscientes implicados na criação artística e a respeito da especificidade psicológica da reação estética o conduziu ao estudo exaustivo da psicologia geral:

Ao se mover da arte para a psicologia, Vygotsky pôde testar suas construções teóricas derivadas de um domínio complexo em um outro domínio. Seu trabalho com a arte capacitou-o a tratar de problemas psicológicos complexos (...) de uma forma muito mais rigorosa do que investigadores com formação em psicologia propriamente dita, na sua época ou na nossa. Foi um mérito - e não um demérito. (Van Der Veer e Valsiner 1996, p. 47) (Grifo meu)

Aqui se tentou demonstrar o interesse pelas artes, sobretudo pela estética cênica, nas origens do pensamento psicológico vigotskiano bem como a importância e a contribuição do teatro na demonstração da validade de suas idéias. A seguir se fará uma exposição sintética da sua Teoria da Reação Estética e o conceito de catarsis que ela implica, conforme são apresentados em Psicologia das artes.

\section{Uma abordagem histórico-cultural da produção artística}

Ao investigar a problemática psicológica inerente à produção artístico-cultural, Vygotsky pretende, em Psicologia das artes, desenvolver, de acordo com os princípios do materialismo histórico, uma análise da criação artística detendo-se especialmente no caráter da ação psicofísica da obra de arte sobre o funcionamento mental dos seres humanos que a produzem e consomem em determinado contexto sócio-histórico. Seu estudo destaca a importância dos vetores histórico-culturais na organização do funcionamento psicológico humano e já explicita seu empenho na construção de uma psicologia que se adequasse ao pensamento marxista soviético: "Considerar a mentalidade de um indivíduo isolado, ou seja, o objeto da psicologia empírica e experimental, de forma tão 
extrassocial como o objeto da mineralogia, significa defender posições diretamente opostas ao marxismo" (1972, p. 31).

Esclarecendo no entanto que: "Os mecanismos sociais de nossa técnica não suprimem a ação dos mecanismos biológicos nem ocupam seu lugar, mas os obrigam a atuar numa direção determinada, submetendo-os (...) O social se estrutura em nosso organismo sobre o biológico, do mesmo modo que o biológico sobrepõe-se ao mecânico" (idem, p. 29).

A sua leitura do fenômeno estético parte do pressuposto de que os próprios sentimentos despertados pela obra de arte eram sentimentos socialmente determinados e que a criação artística era um construto simbólico elaborado consciente e deliberadamente pelo artista - uma espécie de sistema de estímulos, organizados no intuito de provocar um tipo específico de reação no público, a reação estética. Entendidas dessa maneira, as artes deveriam ser consideradas uma forma de conhecimento tão relevante quanto o conhecimento científico, diferindo deste apenas por sua metodologia. Ele discute e assinala algumas contradições da proposta estética formalista russa aliando-se a Eisenstein na defesa da importância dos materiais para a configuração do sentido das produções artísticas, embora ressalte a importante contribuição do formalismo ao ampliar o conceito de forma, entendido como o modo de distribuição e de estruturação do material (conceito que substituiu a categoria conteúdo) na obra de arte.

Um dos principais questionamentos que Vygotsky faz aos formalistas russos é sua excessiva ênfase no processo das criações estéticas. Para ele, o "processo pelo processo", o processo tomado por si mesmo e não direcionado a nenhum propósito, não era um processo mas sim uma farsa, uma ilusão. A argumentação em socorro de seu ponto de vista defende que todo processo não poderia ter um fim em si mesmo por revestir-se, de alguma maneira, de sentido e significado - emprestados pelos objetivos gerais a que se subordinava. Sua crença foi a de que o processo nas artes tinha uma finalidade estética que se justificava pela necessidade psicológica de serem vivenciados os materiais de que se utilizava a forma artística. Em suas críticas ao formalismo ele destaca a contradição evidente entre a necessidade de "sentir os objetos" e de ao mesmo tempo "advertir que uma pedra é uma pedra" por considerar serem esses princípios, nos quais se baseava aquela escola estética, inconciliáveis. Para ele, por causa dessa contradição, se perdia todo o valor original das leis de estranhamento descobertas pelos formalistas uma vez que o objeto do estranhamento tornava-se a percepção propriamen- 
te dita da obra. Esse era o defeito principal do formalismo para Vygotsky, ou seja, aquela incapacidade de compreender a importância psicológica do material e que necessariamente conduzia os formalistas ao exclusivismo sensualista.

Mas suas críticas aos formalistas não o impediram de reconhecer a importante contribuição que aquela corrente artística emprestou, especialmente para a análise psicológica das personagens dramáticas e literárias:

(...) devemos buscar a explicação da psicologia dos personagens e de sua conduta não nas leis psicológicas, mas nos condicionamentos estéticos determinados pelo trabalho do autor. Se Hamlet demora em matar o rei, é preciso buscar a causa não na sua indecisão e falta de vontade, ou seja, na psicologia, mas nas leis que governam a elaboração da estrutura artística. A morosidade de Hamlet não é mais que um procedimento necessário à tragédia, e se Hamlet não mata imediatamente ao rei, isto se deve a que Shakespeare necessitava prolongar a ação trágica por força de leis puramente formais, da mesma forma que um poeta elege as rimas não porque as leis da fonética assim o exijam, mas de acordo com os objetivos da sua criação (...) Seria absurdo buscar a resposta a estas perguntas nas leis da psicologia, porque todas elas têm uma só motivação, a motivação do procedimento artístico, e quem não compreender isso, tampouco compreenderá por que as palavras num verso aparecem ordenadas de forma distinta que no discurso habitual nem qual é o efeito completamente novo que produz esta ordenação artificial do material. (...) os sentimentos não são mais que peças da máquina artística, a correia de transmissão da forma artística. (1972, pp.75-76)

O exame crítico das principais correntes estéticas do início do século XX conduz Vygotsky à conclusão de que o erro de qualquer teoria da arte que parta apenas dos dados objetivos da forma artística ou unicamente da importância do seu conteúdo será o de não considerar em seus fundamentos estruturadores uma perspectiva psicológica capaz de superar a dicotomia entre conteúdo e forma. À análise exclusivamente psicanalítica da produção artística ele se contrapõe, destacando os dois "pecados fundamentais" da psicanálise: 1) Reduzir todas as manifestações da psique humana apenas ao impul- 
so sexual, e, 2) Ao assinalar o papel particularmente importante do inconsciente, esboroar a consciência. Para ele, o desprezo dos momentos conscientes na criação e na recepção artística romperia os limites entre as artes como uma atividade social consciente e a formação inconsciente de sintomas mórbidos nos neuróticos ou da acumulação desordenada de imagens nos sonhos. Suas críticas à psicanálise no entanto não o impediram de reconhecer a grande contribuição que o freudismo trouxe para a abordagem psicológica das artes ao intruduzir o conceito de inconsciente e ampliar a esfera das investigações, sinalizando a maneira pela qual o inconsciente nas artes se torna coletivo e social. Vygotsky considerava que o método psicanalítico e sua aplicação prática no exame das questões estéticas só poderiam vir a ser realmente úteis se renunciassem a pelo menos um dos seus "pecados originais", isto é, quando junto ao inconsciente levassem em consideração a consciência não como um fator passivo, mas como um fator ativo e autônomo responsável pela forma artística; quando renunciassem ao pansexualismo e ao infantilismo e incorporassem à sua esfera de investigação toda a vida humana e não apenas seus conflitos primários e esquemáticos; quando oferecessem uma interpretação sociopsicológica correta do simbolismo das artes e de seu desenvolvimento histórico, compreendendo que as artes não poderiam ser explicadas de maneira conclusiva a partir da reduzida esfera da vida privada, mas que elas exigiam uma interpretação que abarcasse a ampla esfera da vida social.

Após o exame crítico dos principais referenciais teóricos da época para o desenvolvimento de uma abordagem psicológica da criação artística, Vygotsky inicia o assentamento de sua linha de pensamento organizando sua investigação "do simples para o complexo". Ele toma então como objetos de análise três formas da expressão literária: a fábula ("A galinha e a mulher ambiciosa", "O cachorro que levava um pedaço de carne", "O pavão e o corvo", "A raposa e as uvas", "O lobo e a oveIha" entre outras criações e versões de Esopo, Lafontaine e Krilov); o conto ("Respirar tranqüilo" de Bunin) e a tragédia ("Hamlet, príncipe da Dinamarca" de William Shakespeare). O foco central de seu estudo será a unidade estrutural que a fábula, o conto e a tragédia possuem como obras de arte e meios de comunicação-expressão que buscam provocar uma determinada reação estética em seu público alvo. No estudo da fábula são discutidas suas características formais situando-a no âmbito da poesia. Ele ressalta a importância do simbolismo na antropomorfização 
dos animais-personagens e destaca a necessidade de substituição do animal antropomorfizado para manutenção do sentido original da fábula durante a tradução do texto para outros idiomas. Assim, revela que os critérios utilizados nesse procedimento se orientam pelos valores e pelas representações simbólicas das diferentes culturas. As características simbólicas das personagens na fábula são destacadas e justificadas por Vygotsky da seguinte maneira:

1. Por possuírem um caráter mais definido e constante, bastaria que fosse pronunciado o nome de um determinado animal para que se pudesse imaginar o conceito ou força que ele representava (Ex.: o autor da fábula necessita da raposa para com uma só palavra destacar o conceito de astúcia);

2. Porque a antropomorfização permite um distanciamento crítico da personagem, contribuindo na decodificação da moralidade que a fábula encerra, quer dizer, os animais são necessários para atenuar o envolvimento emocional que embota a leitura da moralidade;

3. Por seu caráter simbólico e convencional, essas personagens asseguram a definição das regras para instalação da realidade artística de maneira a possibilitar o efeito estético.

Ao se deter no exame do "Respirar tranqüilo " de Bunin ele retoma os conceitos formalistas de material e forma redimensionados por sua abordagem e os elege como medida para esquadrinhar a estrutura narrativa não-seqüencial (em flashback) daquele conto. Toda sua análise orienta-se por uma concepção dialética da estrutura da obra de arte onde uma nova qualidade é conferida à dinâmica das relações entre material e forma. Vygotsky ressalta o fato de o conto de Bunin possibilitar que o leitor "respire tranqüilo" e de modo semelhante ao da protagonista ao longo da narrativa (na qual o autor selecionou de forma retrospectiva fragmentos dos acontecimentos que conduziram ao assassinato da estudante adolescente Olya Meshcherskaja). Ele destaca a articulação primorosa dos elementos estruturais do conto responsabilizando-a pelo ritmo especial obtido no desenvolvimento do argumento e chama atenção para a distinção entre tempo real e tempo literário - específico da realidade estética. Mas principalmente assinala o fato de o autor, num ritmo de fria serenidade, relatar um assassinato movido pela paixão, produzindo um efeito estético extraordinário a partir do "choque" entre material e forma. 


\section{Hamlet e os fundamentos da criação e recepção estéticas}

Vygotsky escolhe Hamlet de Shakespeare (que houvera sido o tema de seu trabalho de conclusão de curso na Universidade de Moscou) para abordar psicologicamente os princípios estruturais da criação e da recepção da obra de arte. Seu estudo da famosa peça do teatro elizabetano tem como objetivo demonstrar os fundamentos estruturais da tragédia, revisando as idéias contidas originalmente em seu primeiro estudo da obra de Shakespeare. Ele se propõe examinar:

1. O caráter enigmático da obra e as soluções "subjetivas" e "objetivas" defendidas para decifrá-lo;

2. A problemática psicológica implícita ao exame do caráter da personagem-título;

3. A estrutura da tragédia renascentista e suas implicações para o desenvolvimento do tema de "Hamlet";

4. A questão da identificação do público com o herói trágico;

5. A problemática da construção do sentido no discurso artístico.

Vygotsky esclarece que por ser considerada unanimemente uma obra enigmática, a tragédia de Shakespeare tem sido investigada a partir de uma perspectiva interpretativa e, dessa maneira, na tentativa de decifrar o enigma dos motivos pelos quais Hamlet, que deveria ter assassinado o rei imediatamente após o encontro com o fantasma do seu pai mas não o faz, nutrindo-se toda a tragédia das conseqüências de sua inação, os críticos e estudiosos dessa peça buscam as explicações elegendo como ponto de partida de suas análises o caráter e as vivências pessoais da personagem de Shakespeare ou as condições objetivas de estruturação e organização do texto dramático. Para Vygotsky, os que buscam justificativas unicamente na subjetividade do herói trágico, como se ele fosse um ser vivo autêntico, fundamentando sua argumentação na vida e na valorização da natureza humana, fazem com que seus enunciados careçam de qualquer valor científico. $E$ os que defendem as causas da morosidade de Hamlet apenas condicionada pela técnica dramática ou nas raízes histórico-literárias das quais brotaram a tragédia não levam em consideração a liberdade de criação do autor nem as múltiplas possibilidades de tratamento literário de um tema. 
No entanto, ele considerava que se aproximavam mais de uma resposta coerente para elucidação do problema as explicações que atribuíam a morosidade de Hamlet a considerações formais. Quando ele comenta a concepção cênica do espetáculo a partir da peça de Shakespeare levada ao palco do Teatro Artístico de Moscou, sob iniciativa de Konstantin Stanislaviski, Vygotsky condena as "cirurgias" sofridas pelo texto, a ambientação dos acontecimentos na Idade Média e o uso da espada pela personagem a partir do segundo ato. Segundo seu pensamento, essas três operações convertiam a tragédia em algo totalmente oposto ao que o autor havia escrito, limitando o significado e o sentido originais da obra de Shakespeare. E, o mais grave: ratificavam uma concepção "subjetiva" para explicação da maneira de ser da personagem Hamlet, não levando em consideração as convenções cênicas do teatro elizabetano onde a ação se desenvolvia ininterruptamente sobre o palco, sem divisões visíveis em atos, sob os olhos dos espectadores. Para ele, as convenções estéticas do teatro elizabetano teriam influído poderosamente do ponto de vista formal em toda a estruturação daquela tragédia.

Vygotsky alerta para a importância da estrutura da obra como fator decisivo na definição dos motivos e da ação das personagens advertindo no entanto para os riscos de um formalismo excessivo degenerarse em "formulismo", reduzindo assim todo encaminhamento do argumento a "esquemas algébricos". Vygotsky considerava que tanto Shakespeare quanto os dramaturgos em geral não têm em mente a representação, em suas obras, das formas de ser e de pensar de um sujeito particular. Mas isso não implicava reduzir a zero a psicologia das personagens ou afirmar que o caráter do herói é um dado irrelevante, casual e arbitrário. Seu pensamento é o de que a articulação de todos os componentes de uma obra de arte se constitui em algo esteticamente significativo. Por isso, segundo ele, o ponto de partida de uma investigação psicológica da tragédia de Shakespeare deve ser o empenho em livrar Hamlet dos 11 mil volumes de comentários que o tinham oprimido até então com seu "peso" e aos quais teria se referido horrorizado Tolstoi. Vygotsky transcreve trechos dos comentários irreverentes e iconoclastas de Tolstoi sobre o Hamlet de Shakespeare para neles se apoiar, mas deixa claro não estar de acordo com todas as colocações feitas pelo célebre escritor e pensador russo (1972, p. 222). Sua opinião é a de que o "julgamento moral" ao qual Tolstoi submete não apenas Shakespeare como quase toda a literatura (inclusive as suas próprias obras, como o próprio Tolstoi houvera admitido ao fim de sua vida) possuía um caráter abrangente e universal 
que impossibilitava o estudo de casos particulares e até mesmo uma análise psicológica da criação artística. Mas reconhece os aspectos positivos de suas idéias especialmente por ele ter se atrevido, como a criança no clássico conto de Andersen, a dizer que o rei estava nu, que todas aquelas qualidades normalmente atribuídas à tragédia - profundidade, caráter bem definido, penetração na psicologia humana - só existem na imaginação do leitor, que em Shakespeare "nem toda intriga, nem todo desenvolvimento da ação aparecem suficientemente motivados do ponto de vista psicológico, que o caráter de suas personagens muitas vezes não resiste diante da crítica e que além disso existem disparidades escandalosas e absurdas até para o senso comum entre o caráter do herói e seus atos" (1972, p. 223).

Tolstoi considerava não ser possível atribuir a Hamlet nenhum caráter porque seu comportamento denunciava a mais contraditória expressividade e isso impedia, em sua opinião, uma explicação coerente e verossímil de suas palavras e de seus atos. Não é o que pensa Vygostky. Para ele, Tolstoi não aceitou a estética de Shakespeare e isso fez com que ele não pudesse realizar importantes descobertas sobre a clássica personagem do teatro elizabetano. O ponto de vista de Vygotsky é o de que esta "ausência de caráter" encerra em si uma determinada finalidade artística, uma intencionalidade sem a qual não seria possível que Shakespeare atingisse seus objetivos estéticos. E para comprovar seu pensamento defende que Shakespeare criou o mistério de Hamlet partindo de objetivos estilísticos para assinalar a incapacidade da personagem. Para Vygotsky, a principal questão a ser posta não é por que Hamlet demora no cumprimento de seus planos, mas por que Shakespeare o obriga a agir daquela maneira.

$\mathrm{Na}$ tentativa de elucidar os motivos pelos quais Shakespeare teria construído uma personagem como aquela, Vygotsky lembra a "lei da continuidade temporal" inerente à estética cênica do teatro elizabetano. Esta lei estabelecia que a ação deveria decorrer de forma contínua sobre o palco fazendo com que a concepção do tempo na obra seja radicalmente diferente da concepção do tempo real, resultanto absurda qualquer tentativa de discutir o problema da morosidade de Hamlet do ponto de vista do tempo real. Para ele, era impossível resolver a questão da morosidade de Hamlet psicologicamente porque "todos os acontecimentos aparecem medidos e relacionados entre si num tempo convencional, cênico" (1972, p. 226). Sua rigorosa argumentação em defesa da expressividade cênica resultante dos objetivos estéticos perseguidos por Shakespeare na estruturação daquela tra- 
gédia utiliza diversas transcrições de cenas, diálogos e monólogos do texto. Para Vygotsky, a fórmula para entender Hamlet é a dualidade existente entre lenda (Hamlet mata o rei para vingar a morte de seu pai) e argumento (Hamlet não mata o rei senão acidentalmente). Toda a ação ocorre mesclando estes dois planos, que são, a saber: o da firme consciência do caminho a seguir, e o dos desvios desse caminho. Esses dois movimentos da ação dramática, opondo-se, geram uma contradição interna, inerente aos fundamentos da própria obra. Seu ponto de vista é o de que "o efeito de incompreensibilidade era inerente aos próprios objetivos do autor" (1972, pp. 234-235).

Vygotsky destaca a introdução da encenação na encenação como um recurso a mais utilizado por Shakespeare para resolver a questão da falta de verossimilhança. Desse ponto de vista, a cena de metateatro, em que a companhia de comediantes se apresenta ao rei a pedido de Hamlet, obriga as personagens da tragédia a se confrontarem com os "atores" fazendo com que um mesmo acontecimento se ofereça duas vezes, uma como "real" e outra interpretado pelos atores. O desdobramento da ação em sua parte "fictícia" vela e oculta a inverossimilhança do primeiro plano, como num quadro que contém a imagem de outro quadro.

Após elucidar a questão do caráter enigmático da tragédia, atribuindo-o aos objetivos do autor, ele passa a demonstrar como se desenvolve e se expressa a personalidade de Hamlet no contexto da estrutura da obra. Para Vygotsky, o caráter de Hamlet contradizia seu comportamento e suas ações na tragédia. Ele utiliza a psicanálise para demonstrar seu ponto de vista afirmando que "o herói é um ponto na tragédia a partir do qual o autor nos obriga a considerar os demais personagens e todos os acontecimentos" (1972, p. 237).Vygotsky entendia que a identificação do público com o herói era um dos fatores essenciais para que o autor alcançasse a unidade estrutural da obra. Em sua opinião, Shakespeare acompanha a sucessão de acontecimentos na tragédia articulando duas perspectivas: a da personagem-título (protagonista) e a do seu próprio olhar de dramaturgo sobre a peça, ocasionando a superposição de planos psicológicos distintos no contexto de uma mesma ação.

Com a exposição de sua análise do Hamlet Vygotsky acreditava ter superado as abordagens psicológicas "subjetiva" e "objetiva" da peça e conseguido realizar uma síntese dialética da dicotomia que caracterizara até então as principais tendências da crítica e teoria da arte no estudo daquela tragédia. Ele defende a genialidade da obra de Shakespeare especialmente pela fusão entre lenda e argumento na cena da morte do rei. Seu pensamento é o de que esse momento da tragédia se constituía na 
prova definitiva da relevância de sua tese porque "esta inesperada coincidência conferia à tragédia um caráter todo próprio e particular, mostrando, sob uma luz diferente, todos os acontecimentos ocorridos" (1972, pp. 240-241). Naquela cena, sua opinião era a de que o espectador não experimentava nem satisfação nem alívio com a morte do rei, que seus sentimentos, em tensão, não encontravam uma solução banal.

\section{A Teoria da Reação Estética}

O estudo da peça de Shakespeare é o ponto de partida para a formulação da sua Teoria da Reação Estética. Segundo ele, toda teoria da arte se encontrava vinculada aos pontos de vista adotados pelas teorias da percepção, do sentimento e da imaginação ou fantasia. Vygotsky estava convencido de que a abordagem psicológica da criação artística só era possível a partir do desenvolvimento de uma argumentação que se baseasse num desses três aspectos da psicologia humana, ou numa articulação conjunta deles. A premissa básica de sua abordagem psicológica das artes é a diferença entre a reação estética e as reações comuns, causadas por exemplo pelo paladar ou pelo olfato. Ele esclarece que embora a questão da percepção seja um dos problemas fundamentais na abordagem psicológica da criação artística, ela não se constituía no seu eixo central. O epicentro dessa abordagem deveria resultar do cruzamento entre as problemáticas da sensibilidade e da imaginação. Vygotsky ressalta a necessidade de estudos e investigações para elucidarem as questões relativas à emoção e à fantasia - os campos mais problemáticos e desconhecidos da psicologia da época. Ele apresenta o confronto de opiniões e concepções a respeito do sentimento e dos mecanismos mentais que a emoção movimentava ressaltando a dualidade consciência-inconsciência que caracterizava a discussão da afetividade.

A emoção concebida como gasto de energia pela teoria da projeção sentimental de Herder e Lipps será seu primeiro referencial teórico para, comentando-o, expor sua leitura da natureza e do funcionamento da reação estética. De acordo com a Teoria da Projeção Sentimental não é a obra de arte que desperta no público os sentimentos, como as teclas do piano produzem o som, mas sim o público que projeta nos objetos artísticos seus sentimentos. Para Vygotsky, essa teoria, embora sofresse de muitos defeitos, representava um avanço em relação à idéia de Christiansen de que o 
objeto estético infundiria no público suas qualidades emocionais. Ele esclarece que do ponto de vista de uma psicologia objetiva, a Teoria da Projeção Sentimental representava a reação, a resposta ao estímulo e se encontrava mais próxima portanto das leis da reflexologia.

Para Vygotsky, essa "resposta" do público se baseava em mecanismos complexos de percepção da totalidade da obra de arte (forma e material) e não poderia ser explicada apenas pelo esquema estímulo-resposta. Ele considerava que o principal defeito daquela teoria era o de não enxergar a diferença entre a reação estética e as outras reações "biológicas" do organismo. Para responder às questões que ele considerava essenciais na abordagem psicológica da artes nenhuma teoria da emoção estava em condições de explicar a relação interna que existe entre o sentimento e os objetos que se colocam diante da percepção do sujeito. Ele acreditava que para alcançar uma explicação satisfatória seria necessário investigar melhor as relações e inter-relações entre fantasia e sentimento porque "todas as nossas emoções possuem não apenas uma expressão corporal, mas também uma expressão anímica" (1972, p. 257).

Ao levantar a questão da conexão entre emoção e sentimento e fantasia e imaginação ele se refere à Lei da Dupla Expressão Emocional formulada pelo professor Zenkovski em que era demonstrado o fato de toda emoção servir-se da imaginação para projetar uma série de representações e imagens fantásticas, que por sua vez evocavam uma segunda expressão do sentimento. Tomando por base a dupla expressão emocional do sentimento, através da imaginação, Vygotsky apresenta sua Lei da Realidade dos Sentimentos:

Se pela noite em casa confundo um paletó pendurado com um homem, meu erro é evidente, já que minha vivência é falsa e não corresponde a nenhum conteúdo real. Mas o medo que experimento neste caso é verdadeiro. Deste modo, todas nossas vivências fantásticas e irreais se desenvolvem sobre uma base emocional completamente real. Por conseguinte, o sentimento e a fantasia não são dois processos isolados um do outro, mas de fato representam $o$ mesmo processo, e temos direito de considerar a fantasia como a expressão central da reação emocional. (1972, p. 258) (Grifo meu)

Sua Lei da Realidade dos Sentimentos (que pode ter sido influenciada pelo conceito de "fé cênica", ${ }^{8}$ desenvolvido por Stanislavski em seu 
sistema de interpretação teatral) fundia sentimento e fantasia e auxiliava no entendimento da "enigmática diferença" entre o sentimento artístico e o sentimento habitual. Vygotsky observou que tanto no jogo do "faz-de-conta" infantil como nos processos de representação artísticos ocorria uma retensão da reação emocional porque "a criança que brinca de luta detém o movimento da mão disposta a acertar o golpe em seu companheiro de brincadeira" (1972, p. 259). Ele esclarece que tanto o sentimento esteticamente determinado como o sentimento habitual, embora fossem formas de sentir muito semelhantes, originavam-se de processos psicológicos distintos. O sentimento artístico se constituía e se mantinha através da imaginação, que o reforçava, e isso fazia com que a expressão dos sentimentos e emoções suscitados pelo "faz-de-conta" infantil, pelo teatro ou pela obra de arte fosse de alguma maneira contida e "controlada", embora possuísse grande intensidade. Para ele, "as emoções das artes são emoções inteligentes" (1972, p. 260).

Vygotsky demonstra que na reação estética se configurava uma contradição original que era expressa exemplarmente por Diderot em seu Paradoxo do comediante no qual revelava que o ator chorava com lágrimas de verdade mas que suas lágrimas brotavam de seu cérebro. No sentido de explicar esta contradição Vygotsky apóia-se no princípio de antítese de Charles Darwin segundo o qual determinados atos, ao se associarem a certas sensações ou sentimentos, causavam atos involuntários em decorrência da associação gerada com o hábito do efeito daquelas sensações e daqueles sentimentos. Vygotsky caracteriza a especificidade da reação estética destacando nela a retensão e o controle das manifestações exteriores da emoção. Nos seus estudos da fábula, do conto e da tragédia ele acreditava ter demonstrado como essa contradição afetiva suscitava sentimentos opostos uns aos outros e provocava um curto-circuito que os aniquilava. Para ele, era esse efeito que caracterizava toda e qualquer criação artística: a reação estética. Essa reação especificamente humana, obtida a partir da contradição subjacente à estrutura das obras de arte, é o fundamento sobre o qual ele vai erigir seu conceito de catarsis.

\section{O conceito vigotskiano de catarsis}

Esclarecendo que não pretende com a palavra catarsis se reportar ao conceito de Aristóteles ou elucidar o significado que o pensador 
grego Ihe pretendia atribuir em sua Poética, Vygotsky relaciona os sentidos em que a palavra fora utilizada por Lessing (ação moral da tragédia, a conversão das paixões em inclinações virtuosas), E. Müller (a passagem do desprazer ao prazer), Bernays (cura e purificação no sentido médico) e Zeller (anestesia do sentimento), advertindo que nenhuma dessas interpretações se adequava ao significado que ele the pretendia conferir. Vygotsky denomina catarsis a reação estética:

(...) nenhum outro termo dos empregados até agora em psicologia expressa de forma tão completa e clara o fato, fundamental para a reação estética, de que os afetos dolorosos e desagradáveis se vejam submetidos a certa descarga, a seu aniquilamento, a sua transformação em sentimentos opostos, e de que a reação estética como tal se reduza de fato à catarsis, ou seja, a uma completa transmutação de sentimentos. (1972, p. 263) (Grifo do autor)

Ele explica que a base da catarsis (reação estética) reside no caráter contraditório implicito à estrutura das criações artísticas, na oposição entre material e forma. A sua Teoria da Reação Estética estabelece que os sentimentos evocados pela obra de arte são retroalimentados pela fantasia ou imaginação e se encontram nela conscientemente organizados para a obtenção da catarsis (reação estética). Vygotsky esclarece contudo que o desenvolvimento da formulação das artes como artefatos culturais, elaborados com o intuito de provocar uma reação emocional específica, a catarsis, não é o objetivo do seu estudo embora contribuísse para lançar luz sobre esse aspecto central da reação estética, eleito como princípio explicativo fundamental das suas investigações.

Ele destaca na poesia a "luta" entre as propriedades fonéticas "naturais" do material verbal e a forma imposta pela métrica, que conduz ao ritmo (síntese e solução catártica das suas interações, correlações e oposições) assinalando mais uma vez a necessidade de se compreender a forma como um todo dinâmico que ultrapassa a simples soma ou fusão dos seus elementos constituintes.

Ambicionando demonstrar sua Teoria da Reação Estética na literatura ele elege a novela Eugênio Oneguin de Pushkin na qual o leitor é surpreendido pela paixão do conquistador Eugênio por Tatiana - que o leva à morte. Explicita, utilizando-se de citações, as variações dinâmicas do caráter do herói paralelamente às mudanças no curso da ação na nove- 
la. Para ele, essa mudança no caráter da personagem é um dos procedimentos mais importantes para que o autor alcance o objetivo maior da criação artística: a reação estética, a catarsis. Vygotsky também demonstra a validade de sua teoria no teatro ressaltando que no drama a visualização da contradição entre os elementos artísticos é obscurecida pelo fato de o conflito se constituir no material por excelência da criação dramática. E assinala a incompletude da literatura dramática como elemento complicador da percepção da forma artística: “(...) todo drama não é uma obra de arte acabada, mas apenas o material para uma representação de teatro; por isso, distinguimos com dificuldade o conteúdo da forma no drama, o que dificulta sua compreensão" (1972, p. 279) (grifo meu).

Mais uma vez elegerá Shakespeare para fazer demonstrar a validade de suas idéias. Escolhe Otelo, por considerar muito nítida naquela peça a contradição entre o caráter e as ações da personagem-título. Para Vygotsky, o saber expressar a variação no sentimento em um determinado caráter é a base para uma concepção dinâmica da personagem na obra de arte. Sua predileção por Shakespeare é justificada pelo fato de na obra do dramaturgo inglês ser possível enumerar muitos exemplos, extraídos de suas tragédias e comédias, que provavam claramente esse desenvolvimento dinâmico do caráter da personagem em função da estrutura da obra. Ele considerava o tratamento dado por Shakespeare a suas personagens absolutamente de acordo com a regra aristotélica de estruturação da tragédia segundo a qual a lenda ou o mito é o princípio e a alma daquele gênero dramático, seguidos de perto pelo caráter das personagens. Seu pensamento é o de que a ampla e livre pintura do caráter das personagens shakespearianas tem como objetivo não a aproximação com pessoas reais, mas, ao contrário, complicar e enriquecer o desenvolvimento da ação e do esquema dramáticos.

Ao longo da demonstração de aplicabilidade de sua Lei da Reação Estética ao teatro, ele estende sua validade para todo e qualquer gênero dramático. Vygotsky estabelece características distintivas entre tragédia e drama a partir da composição do caráter das personagens. $\mathrm{Na}$ tragédia, o herói possui e encarna uma força titânica e é considerado uma espécie de deus: seu caráter superior maximizaria os acontecimentos e as emoções. Nesse gênero dramático uma lei absoluta é transgredida por uma força absoluta numa luta heróica. Assim, quando a tragédia renunciasse à sua grandeza, ao "maximalismo", ela se converteria em drama. Seu pensamento é o de que o drama seja caracterizado sobretudo por seus protagonistas possuírem um caráter encontrado no cotidiano, 
próximo ao das pessoas comuns de "carne e osso". Vygotsky também ressalta a função social e didática da tragédia na Grécia antiga como aparelho ideológico do Estado grego, na medida em que a transgressão da ordem "olímpica" implicava a punição exemplar do "herói", garantindo a manutenção dos direitos adquiridos pelos "deuses", aristocratas latifundiários helênicos.

A demonstração da aplicabilidade de sua Teoria da Reação Estética na comédia localiza a catarsis no riso que as personagens provocam no público e destaca a separação nítida, neste gênero dramático, entre os pontos de vista do espectador e da personagem. Ele recorre a Henri Bergson para demonstrar os fundamentos sociais do riso. Vygotsky também examinou o princípio de antítese e a validade de sua Lei da Reação Estética no drama. Escolheu duas peças de Tchecov: As três irmãs e $O$ Jardim das Cerejeiras porque as suas tramas eram baseadas em relações cotidianas reais mas perpassadas por motivos simbólicos (a ida para Moscou desejada pelas três irmãs e a desgraça que representava a venda do jardim para Ranévskaia). Esses elementos "imotivados" do drama, isto é, a luta desses motivos irreais para que fossem aceitos psicologicamente como reais pelo público, seria a base da contradição necessária àquelas obras de arte para que possibilitassem a catarsis.

Ele considerava que o teatro, do ponto de vista cênico (atuação de atores e espetáculo), era ideal para demonstrar a validade de suas idéias. E mais uma vez utiliza o funcionamento mental do ator na cena como paradigma do caráter dual da emoção que experimentava o público na recepção estética.

Vygotsky passa a examinar a catarsis nas artes plásticas e elege entre elas o desenho como ideal para a exposição de suas idéias pelo fato de este não mascarar, como a pintura o fazia, o suporte utilizado para suas representações: No desenho, a representação de um espaço ou forma tridimensional conservava o caráter plano do suporte sobre o qual ela era construída. Ele identifica a catarsis na escultura e na arquitetura destacando o contraste entre os materiais escolhidos e as propriedades dos objetos representados.

A demonstração da sua Teoria da Reação Estética nos diversos domínios da criação artística apresenta a arquitetura gótica como excelente ilustração do seu pensamento ao assinalar naquela forma de expressão tectônico-plástica o contraste obtido a partir do confronto entre o peso do material utilizado e a "leveza" e o "movimento" das formas re- 
presentadas. Vygotsky continua seu estudo enfatizando a importância das artes na elucidação do sistema geral da conduta humana com base em seu conceito de catarsis e no reconhecimento da especificidade da reação estética.

\section{Conclusão}

Diante das principais idéias defendidas por Vygotsky em Psicologia das artes não é difícil admitir que seu interesse na investigação do funcionamento mental subjacente à criação e recepção estéticas o teria conduzido ao aprofundamento de estudos da psicologia humana. Ao examinar as centenas de páginas dessa sua primeira incursão no universo da psicologia, será possível constatar que ali já se encontra em germinação sua reflexão sobre a mediação semiótica cultural e o rigor da metodologia materialista dialética no exame de alguns aspectos da mente humana. Suas investigações e pesquisas subseqüentes forneceram as bases sobre as quais se erigiu a Teoria Histórico-Cultural do Desenvolvimento Humano, na qual se fundamenta a Psicologia Sócio-Histórica. A atitude científica vigotskiana caracterizou-se ao longo de toda sua extensa produção (mais de 180 textos) por uma assimilação crítica que incorporava as contribuições válidas de diferentes perspectivas sobre os seus objetos de estudo. Para ele, o ser humano teria sido forjado por instrumentos psicológicos da ordem do simbólico, que emergiram forçosamente do processo comunicacional e interativo necessário ao trabalho, coletivo, de transformação e domínio da natureza.

A perspectiva histórico-cultural do desenvolvimento proposta por Vygotsky, na medida em que lançou as bases para uma abordagem holística das investigações biológicas e sociais do ser humano, é considerada por alguns estudiosos tão importante para a ciência como a descoberta do código genético (Imbert 1972, p. 519).

\section{Notas}

1. O título original do texto de Vygotsky é Psikológuia iskustva. Este artigo utiliza a tradução livre da versão espanhola de Victoriano Imbert intitulada Psicologia 
del Arte, publicada pela Barral Editores, em 1972. Optou-se pela expressão Artes, no título e ao longo do texto, sempre que esta se referir às diversas linguagens artísticas (teatro, dança, música, literatura). A palavra arte aqui será utilizada apenas para designar as artes plásticas (desenho, pintura, escultura).

2. Escrito em 1925, Psicologia das artes permaneceu inédito até 1965, 31 anos após a morte do autor, na Rússia (Schnaiderman 1978, p.103). Em 1972 foi publicado pela Barral Editores (Barcelona-Espanha), que adquirira os direitos sobre o texto em língua espanhola desde 1970. Em 1971 surge a edição norte-americana The psychology of art sob iniciativa de The M.I.T. Press (Cambridge-Mass). Psicologia das Artes foi publicado em português pela editora Martins Fontes, em 1998, após a redação deste artigo, com tradução de Paulo Bezerra e revisão do ator do Teatro Oficina/SP Vadim V. Nikitin.

3. O antigo calendário juliano ou bizantino adotado na Rússia Tzarista é 12 dias atrasado em relação ao calendário gregoriano ocidental atual. Pelo calendário gregoriano, corrigida a diferença, Vygotsky teria nascido aos 17 de novembro daquele ano.

4. Não se tem conhecimento até aqui de nenhuma tradução para outro idioma desse trabalho de Vygotsky.

5. A diferença básica entre reação e reflexo na psicofisiologia é que a primeira diz respeito às ações de um organismo vivo, sem sistema nervoso, em resposta a estímulos do meio. Os reflexos portanto caracterizam o comportamento de organismos com sistema nervoso. Cientistas na época de Vygotsky se referiam às reações humanas como reflexos e passaram a designar a ciência das reações de organismos vivos de reflexologia, evitando a expressão reatologia (Vygotsky 1997, p. 15).

6. Alexander Romanovich Luria, psicólogo e neuropsiquiatra russo, foi colaborador e amigo de Vygotsky integrando a "troika" (grupo de pesquisa liderado por Vygotsky, junto ao Instituto de Psicologia de Moscou, que também contava com a participação de A.N. Leontiev).

7. O professor Michael Cole gerencia uma lista de discussão na Internet, do Laboratório de Cognição Humana Comparada da UCSD que discute os pressupostos filosóficos e as implicações pedagógicas e metodológicas da Teoria Histórico-Cultural do Desenvolvimento, elaborada a partir da perspectiva sócio-histórica adotada por Vygotsky na abordagem dos eventos vinculados às funções psicológicas superiores. O endereço eletrônico do professor Cole é: <mcole@weber.ucsd.edu>. Interessados em fazer parte da lista de discussão devem enviar sua solicitação de ingresso para: xmcarequest@weber.ucsd.edu

8. O conceito de "fé cênica" desenvolvido por K. Stanislavski em seu sistema de interpretação realista refere-se à necessidade de o ator acreditar na realidade cenicamente estabelecida como se fosse, de fato, verdadeira. 


\section{The arts and the cultural development of the human being}

ABSTRACT: This paper presents the historical and social context in which Vygotsky wrote his "Psychology of Art". It's recognized in such work the origins of vigotskian thought over which the Cultural-Historical Theory of high mental functions has been constructed. It exposes his 'Esthetic Reaction Theory and Catarsis' concept.

\section{Bibliografia}

BLANCK, Guillermo. "Vygotsky: O homem e sua causa". In: MOLL, Luis C. Vygotsky e a educação. Porto Alegre: Artes Médicas,1996, pp. 31-55.

CAVALIERE, A. O inspetor geral de Gógol/Meyerhold. São Paulo: Perspectiva, 1996.

COLE, Michael. Epílogo. "Um retrato de Luria”. In: LURIA, A.R. A construção da mente. São Paulo: Ícone, 1992, pp. 193-228.

DAVYDOV, V.V. e ZINCHENKO, V.P. "A contribuição de Vygotsky para o desenvolvimento da psicologia". In: DANIELS, Harry (org.). Vygotsky em foco: Pressupostos desdobramentos. Campinas: Papirus, 1994, pp. 151-167.

IMBERT, Victoriano. Epílogo. "Comentários psicologia del arte". In: VYGOTSKY, L.S. Psicologia del arte. Barcelona: Barral,1972, pp. 511-517.

RIPELLINO, A.M. Maiakóvski e o teatro de vanguarda. São Paulo: Perspectiva, 1971 .

O truque e a alma. São Paulo: Perspectiva, 1996.

SCHNAIDERMAN, B. A poética de Maiakóvski. São Paulo: Perspectiva, 1978 .

. Projeções: Rússia/Brasil//tália. São Paulo: Perspectiva, 1984.

VAN DER VEER, René e VALSINER, Jaan. Vygotsky: Uma síntese. São Paulo: Loyola, 1996.

VYGOTSKY, L. S. Psicologia del arte. Barcelona: Barral, 1972.

. Educational psychology. Flórida: St. Lucie Press, 1997. 